\title{
Arguing from Ignorance
}

$2.1 \quad$ Introduction - $\mathbf{3 0}$

2.2 Attitudes to Ignorance - 32

2.3 Logic and Ignorance - 40

2.4 Arguing from Ignorance in Medicine and Health - 47

2.5 Ignorance as a Cognitive Heuristic - 56

Chapter Summary - 57

Suggestions for Further Reading - 58

Questions - 59

Answers - 61

References -63 
LEARNING OBJECTIVES: Readers of this chapter will

- be able to discern when ignorance is an undesirable state or disposition that should be avoided, and when ignorance can be gainfully employed in our various deliberations.

- be able to recognize the conditions under which a knowledge base may be said to be closed, and the linguistic markers of this closure.

- be able to recognize the conditions under which a knowledge base may be said to be extensively searched, and the linguistic markers of this search.

- be able to identify when a knowledge base has been closed prematurely, for example, in advance of an investigation, often with a view to forcing the hearer's acceptance of the conclusion of an argument from ignorance.

- be able to identify when a knowledge base has been only partially searched, and understand the implications of an inadequate search for the rational warrant of the resulting argument from ignorance.

- be able to understand the epistemic gains that derive from the use of the argument from ignorance as a cognitive heuristic in our thinking and reasoning.

\subsection{Introduction}

The word 'ignorance' has some rather negative connotations. In general, ignorance is a mental state or condition of existence that most people want to avoid. We undertake study at school, college, and university with a view to acquiring knowledge and ridding ourselves of ignorance. We watch television programmes about astronomy, politics, and history because we want to be well informed and knowledgeable about the world around us. We experience affirmation when we are told that we have extensive knowledge of a topic or discipline, and embarrassment or even shame when our lack of knowledge or ignorance in an area is exposed. Ignorance can cause us to fail an examination, prevent us from obtaining an academic or professional qualification, and lead to negative appraisal from an employer. With such negative consequences related to a lack of knowledge, it seems strange for anyone to claim that ignorance can be a valuable resource, particularly when we are engaged in reasoning and decision-making in medicine and health. Yet, that is exactly what I will claim in this chapter. It will be argued that ignorance is too often disparaged when it is, in fact, central to many of the deliberations that we engage in on a daily basis. By way of illustration, consider the following scenario. I want to attend a cousin's wedding in Dublin and decide that I should make the trip by train. I walk into the train station on my way home from work and pick up a timetable. It shows that there are two stops on the journey from Belfast to Dublin. These stops are at Dundalk and Drogheda. A friend later enquires if she can travel with me on the train as she wants to attend a music festival in Newry. She asks me if the Dublin train stops at Newry. I reply that it does not.

This scenario will not strike the reader as remarkable in any way. In fact, it is typical of the many everyday interactions that each of us undertakes with little effort or reflection. But there is a real sense in which my response does reveal something significant. What it 
reveals is the ease with which I am able to employ ignorance to answer my friend's question. The reasoning that resulted in my response can be reconstructed as follows:

I have no evidence or knowledge that the train stops in Newry.

Therefore, the train does not stop in Newry.

I have used an argument from ignorance to answer my friend's question. The premise of this argument lays bare my lack of knowledge or ignorance. I use this lack of knowledge to conclude that the train does not stop in Newry. Moreover, I draw this conclusion quite legitimately. After all, if the train did stop in Newry, this should be shown in the timetable. The fact that Newry does not appear in the timetable is all the grounds I need to conclude that the train does not stop at Newry. In the next section, it will be shown that this argument satisfies two conditions on the use of the argument from ignorance, or at least the non-fallacious use of this argument. We will see in this chapter that there are many other circumstances where an argument from ignorance is not rationally warranted. But first, let us consider another scenario where this argument is employed, this time in an issue related to medicine and health. A new cholesterol-lowering drug is undergoing clinical trials before it is launched onto the market. The pharmaceutical company that is developing the drug has tested it on 10,000 human subjects with elevated blood cholesterol in centres in the USA, UK, France, Australia, and China. The purpose of the trials is to establish that the drug is effective in lowering blood cholesterol, and that it can do so without causing harm in the form of adverse reactions or side-effects. A panel of independent experts in pharmacology is brought together to examine the results of these trials. After a wide-ranging review of the evidence, the panel concludes as follows:

There is no evidence that drug $X$ causes harm.

Therefore, drug $X$ does not cause harm.

This argument has the same form as the 'train' argument above. The panel has argued from a lack of evidence (or knowledge) that the drug causes harm to the conclusion that it does not cause harm. Like the 'train' argument, this use of the argument from ignorance is also warranted. After all, a large multi-site trial involving 10,000 participants has been conducted. Also, the results of the trial have been reviewed by a panel of experts in the area. If the drug did cause harm, the trial and subsequent review would reveal that to be the case. Because there is no evidence of harm, the panel can safely conclude that the drug does not cause harm. This argument illustrates yet again that there are certain contexts in which arguing from a state of ignorance or lack of knowledge (or evidence) is warranted. Moreover, these contexts are as likely to involve expert scientific issues such as drug safety as they are more mundane issues like planning a train journey. The logical merits of the argument remain the same regardless of whether the argument is advanced by scientific experts or lay people. This fundamental observation will resonate throughout the chapters in this book.

The sections in this chapter will unfold as follows. In $>$ Sect. 2.2, we consider some of the reasons logicians, philosophers, and others have given for rejecting the 
use of the argument from ignorance. It will be argued that the characterization of this argument as a weak, fallacious, or invalid form of reasoning usually betrays certain assumptions about what it means to know something. These assumptions contain hyperbolical standards for knowledge which, it is claimed, no practically-situated rational agent can attain. In $>$ Sect. 2.3, we examine the logical and epistemic conditions under which use of the argument from ignorance is rationally warranted. These conditions-a closed world assumption and an extensive search criterion-were fulfilled in the arguments from ignorance examined above. There are many situations, however, where these conditions are not fulfilled and the argument is unwarranted in consequence. In $>$ Sect. 2.4, we examine some of those situations within a wider assessment of the use of the argument from ignorance in medical and health contexts. Finally, in - Sect. 2.5, we consider some of the ways in which reasoning in medicine and health can be facilitated by use of the argument from ignorance. On these occasions, it is useful to conceive of the argument as a cognitive heuristic or a mental shortcut that bridges gaps in our knowledge. An examination of the features of this heuristic-we will call it an ignorance heuristic-will conclude the discussion of this chapter.

\subsection{Attitudes to Ignorance}

We do not need to search far to find negative attitudes towards ignorance. Comments about a person's state of ignorance are one of the most common forms of personal insult or abuse. Expressions such as "You are an ignorant idiot!" and "What ignorant twit forgot to lock the door?" are part of everyday language use. Politicians attack the ignorance of their opponents with predictable regularity. During a parliamentary debate on energy price in the House of Commons in the UK, Conservative Member of Parliament, Sir Alan Duncan, addressed his Labour opponent in the following terms:

॥ The idea that a regulator can suddenly say, "Oh, there's the wholesale price, therefore there is the retail price", is total lunacy and ignorance, of which the right honourable Lady should be ashamed. (House of Commons, 14 January 2015)

Sometimes, the target of a political attack on ignorance is implied rather than explicitly stated. During his commencement address at Rutgers University in May 2016, Barack Obama made the following pointed remarks. They were clearly aimed at presidential challenger Donald J. Trump:

॥Class of 2016, let me be as clear as I can be. In politics and in life, ignorance is not a virtue. It's not cool to not know what you're talking about. That's not keeping it real or telling it like it is. That's not challenging political correctness. That's just not knowing what you're talking about. And yet we've become confused about this.

Ignorance is also widely credited as the cause of discrimination and prejudice in society. Intolerance towards other people on grounds of race, gender, sexuality, and religion, it is argued, results from a lack of knowledge or ignorance about cultures, identities, and ways of life that differ from our own. Conflict between peoples and nations is also attributed to ignorance. The role of ignorance in these seemingly 
intractable human problems is clearly identified in the Constitution of the United Nations Educational, Scientific and Cultural Organization (UNESCO). The opening paragraphs to the Constitution, which was signed on 16 November 1945 and ratified by 20 countries on 4 November 1946, read as follows:

I) The Governments of the States Parties to this Constitution on behalf of their peoples declare:

That since wars begin in the minds of men, it is in the minds of men that the defences of peace must be constructed;

That ignorance of each other's ways and lives has been a common cause, throughout the history of mankind, of that suspicion and mistrust between the peoples of the world through which their differences have all too often broken into war;

That the great and terrible war which has now ended was a war made possible by the denial of the democratic principles of the dignity, equality and mutual respect of men, and by the propagation, in their place, through ignorance and prejudice, of the doctrine of the inequality of men and races.

Beyond politics, social equality, and international relations, ignorance is at the heart of many of the most pressing challenges in public health. The emergence of the AIDS epidemic in the 1980s prompted governments around the world to launch public health campaigns. In the UK, the Conservative government led by Margaret Thatcher responded to the growing threat of this new infectious disease by launching the AIDS Don't Die of Ignorance' campaign. A leaflet bearing these words was sent to every household in the UK (see - Fig. 2.1). It was accompanied by an extensive television campaign that also warned of the risks posed by this new disease. Worldwide, ignorance of AIDS was costing many thousands of people their lives. The only public health tool available to stem the rapidly growing number of new cases was to increase people's knowledge of how the disease was transmitted and of the preventative measures that could be taken. Consequently, the battle against ignorance was to become the central theme of HIV/AIDS public health campaigns around the world, and is still the case today (see $\bullet$ Fig. 2.2).

In short, ignorance has little to commend it. It contributes to human conflict, discrimination and prejudice, and is a significant factor in the spread of infectious disease. With ignorance as the source of so much human suffering, it will seem strange to the reader that I should now propose that ignorance be positively embraced under certain circumstances. Those circumstances are represented by the 'train' argument in Sect. 2.1. There is a general expectation that a train timetable will be complete, that is, that it will show all the stops that the train makes in a particular journey. It is accordingly reasonable to conclude that if stop $X$ is not indicated on the timetable, then the train does not take in stop $X$ on its route. The reasoning in this case is a deductively valid modus tollens inference:

If $P$, then $Q$

Not-Q

Therefore, not $P$
If the train stops at $X$, then $X$ would appear in the timetable. But $X$ does not appear in the timetable. Therefore, the train does not stop at $X$. 


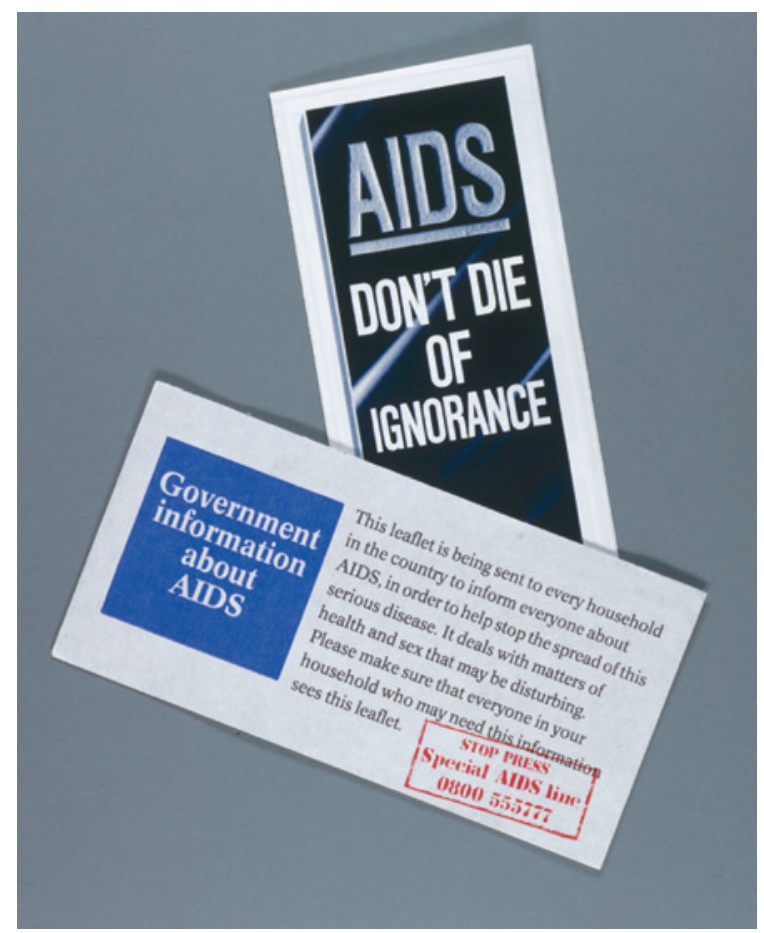

- Fig. 2.1 UK Government AIDS awareness leaflets, 1987 (Science Museum, 1986-1987. Object No. 1994-75. ( T) This image is available for use under the following license: CC-BY-NC-ND 2.0)

But neither of the premises from which this inference is drawn mentions ignorance or a lack of knowledge. So where does ignorance enter into this two-premise argument? Ignorance is the source of the rational warrant for the two premises in this argument. In $>$ Sect. 2.1, we said that two conditions needed to be fulfilled for use of an argument from ignorance to be rationally warranted. Those conditions are a closed world assumption and an extensive search criterion. The closed world assumption is an assumption to the effect that a knowledge base is complete in the sense of containing all relevant information in a particular domain. This assumption provides rational warrant for the first premise above-the train timetable is a complete knowledge base of all train journeys and the stops within those journeys. The extensive search criterion requires that the knowledge base in a particular domain is extensively searched. That criterion is satisfied when I open the timetable, locate the particular journey I want to undertake, and search all the stops that will be made as part of that journey. This criterion provides rational warrant for the second premise above. It is because the closed world assumption and the extensive search criterion are so robust in the case of the 'train' argument that they can provide the strongest possible rational warrant for the premises in this deductively valid argument. But let us be under no illusion about either of these conditions. The only reason they have any leverage at all in the above argument is because there is a complete, extensively searched knowledge base 

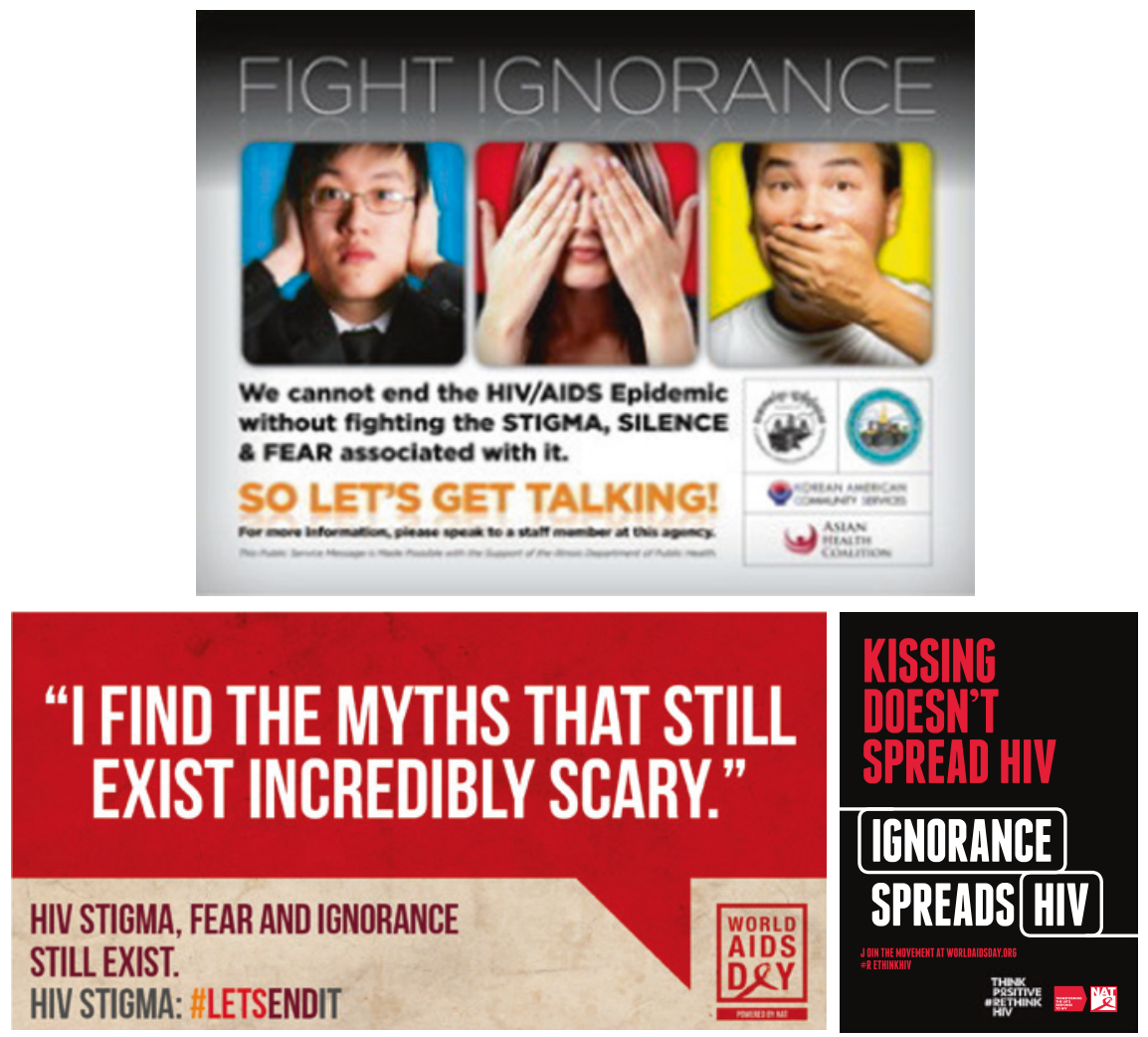

- Fig. 2.2 The emphasis on fighting ignorance is evident in these campaign posters. The Asian Health Coalition launched the 'Fight Ignorance' campaign in 2011-2012 with the aims of reducing misinformation and stigma surrounding HIV/AIDS in Asian American communities (reproduced with the permission of the Asian Health Coalition). Ignorance is also the target of the 'Think Positive: Rethink HIV campaign' (2015) and the 'Let's End It' campaign (2017) of the National AIDS Trust in the UK (Copyright NAT [National AIDS Trust])

that does not contain knowledge of $X$ or $Y$ (where $X$ and $Y$ could be propositions in a knowledge base). The ignorance at the centre of an argument from ignorance is exactly this 'missing' or 'absent' knowledge.

The idea that the absence of knowledge (i.e. ignorance) can be grounds on which to draw a conclusion in argument strikes many observers as a decidedly weak form of reasoning. This was clearly demonstrated in an experimental investigation of reasoning that was conducted in 879 members of the general public in the UK (Cummings 2015). The argument from ignorance was one of four types of reasoning investigated in this study (Cummings 2014). Among some of the responses made by participants was the following remark about a food additive that had been used for 40 years without consequences for human health. The absence of ill health effects during this time, it was commented, did not constitute proof that the additive was safe: 
I) The additive has been widely used for 40 years and during that time numerous tests have been undertaken. That suggests safety, but doesn't constitute proof of it (62-year-old, university educated, white British man)

Statements based on a lack of evidence were judged by some participants to be an inadequate basis for knowledge. In such cases, it was considered that doubt still remained:

I) The text states "there is no evidence that scrapie was transmissible to humans". This statement leaves me with doubt, therefore, I don't know (50-year-old, university educated, white British woman)

I) The statement "there is no evidence that the asthma drug is unsafe" leaves some doubt that it is generally safe to all groups (59-year-old, university educated, white British woman)

The absence of evidence left some participants with a sense of uncertainty that something was or was not the case. This was variously expressed, with some participants reporting a lack of confidence, while others said they were not sure about what to conclude:

I) 'No evidence that the vaccine was unsafe' doesn't instil me with confidence that it is safe (30-year-old, university educated, white British woman)

I) I personally am not $100 \%$ sure it was safe (45-year-old, secondary school educated, white British man)

For these participants, notions such as proof, knowledge, doubt, and certainty are bound up with epistemic standards that are not satisfied by an absence or lack of evidence. For this reason, any claim based on such evidence should be rejected or at least treated with great caution and even suspicion. The opinions of these lay participants are not dissimilar from those expressed by professional philosophers and logicians, many of whom reject an absence of knowledge or evidence as anything but the weakest possible grounds upon which to accept a claim in argument. Robinson (1971) is unambiguous about the lack of merit in an argument based on ignorance. He states:

॥ The argument from ignorance is bad. Ignorance is not one of the sources of knowledge; and premises about our ignorance do not reasonably give conclusions about our knowledge. Ignorance is a good ground for suspending judgement, but not for taking a side. (102)

Toulmin et al. (1984) are no less negative in their rejection of the argument from ignorance. This argument, they claim, leaves us that "we cannot certainly infer anything at all" (145). In fact, they go even further in their dismissal of this argument when they claim that it 'trivializes' the notion of evidence itself:

॥ To provide backing for such a warrant, we should have to argue that lack of proof is itself a kind of evidence, and this would trivialize the concept of evidence beyond recognition. (1984: 146, italics in original) 
LeBlanc (1998) also sees little merit in the argument from ignorance, which she describes as "not very informative". She goes further when she states:

॥ From a premise of ignorance, we cannot conclude anything but mere possibility, and many things are possible. (191)

Most recently, Kelley (2014) queries whether any judgement can be reasonably based on a lack of knowledge or evidence. He argues that:

॥ The absence of evidence usually means that we simply don't know enough to make a judgement. Such ignorance cannot be transmuted into knowledge, any more than brass can be transmuted into gold. (130)

These views of lay people and professional philosophers have something important in common. It is a belief that concepts such as knowledge, proof, and evidence should be held to exacting epistemic standards. Moreover, it is against these standards that the argument from ignorance is judged to be inherently weak as a form of reasoning. But where exacting epistemic standards can become problematic is when they lead us to reject all sorts of rational inquiries according to which we can claim to know that something is true. In other words, exacting epistemic standards can sometimes be allowed to run amok and become standards that are so hyperbolical in nature that no practically-situated rational agent could possibly attain them. I contend that this has been the fate of the concept of knowledge. Knowledge has become so imbued with inflated epistemic standards that it seems that there are no circumstances in which we can rightfully say that $X$ knows that $p$. So construed, knowledge is not an exacting epistemic concept but an unattainable concept. Nicholas Rescher (1980) captures this same inflation in the concept of certainty that leaves us with a pervasive scepticism in which we can never truly be said to know anything at all:

I) One must distinguish between mundane or practical (or "effective") certainty on the one hand and transcendental or categorical (or "rigid") certainty on the other. The former is certainty "beyond any reasonable doubt", the latter certainty "beyond any possible doubt at all - be it reasonable or otherwise". And the certainty we claim for our knowledge is of the former, and not necessarily of the latter kind. (1980: 37, italics in original)

Hyperbolical epistemic standards such as transcendental certainty serve only to distort the concept of knowledge. If we can reclaim knowledge from these standards, as I believe we can, then we have a reasonable prospect of acknowledging all the different ways in which we can claim to know that something is true. One of those ways is to use the absence of knowledge or evidence of a proposition within an appropriately circumscribed domain as a basis of a claim to knowledge. This is, in effect, the type of reasoning that occurs in an argument from ignorance. When evaluated against appropriate epistemic standards, as I am proposing should be the case, an argument from ignorance is a productive source of claims that can be used in decision-making and other types of judgement. In some cases, these claims have the rational warrant of knowledge itself. But even when the conclusion of an argument from ignorance is not a known thesis, but a presumed thesis, it is not because the conclusion falls short of 
some hyperbolical standard of what it means to know that something is true. Rather, it is simply that on a particular occasion of use, the argument lacks some of the rational warrant that is present on other occasions of use. This is the position that has been taken by Douglas Walton, one of many informal logicians who have adopted a more benign view of the rational merits of the argument from ignorance. Walton (1996) has been explicit about the need to develop frameworks of argument evaluation that fall within the rational resources of practically-situated arguers. Within these frameworks, many so-called fallacies appear not so fallacious after all. This is also the case for the argument from ignorance:

I) Presumptive reasoning [...] is closely related to a type of argument called the argumentum ad ignorantiam (argument from ignorance), traditionally held to be a fallacy. However, arguments from ignorance are not always fallacious. In many cases, absence of knowledge to prove a proposition constitutes good presumptive grounds for tentatively accepting that proposition as a commitment [...] Presumptive reasoning enables practical reasoning to go ahead in variable circumstances where knowledge is incomplete. (1996: 153)

This is the view of the argument from ignorance that will inform the rest of this chapter. There is nothing inherently fallacious about this argument. Rather, it is more or less rationally warranted in certain contexts of use. Many of those contexts relate to medicine and health. The task of each of us as we attempt to evaluate an argument from ignorance is to establish the features of the context in which it is used that make it more or less rationally warranted. We will see in $>$ Sect. 2.3 that this task is not as easy as it sounds. It can involve background knowledge of a topic or discipline and some quite sophisticated logical and epistemic judgements.

\section{SPECIAL TOPIC: Ignorance and health}

It is worth adding a cautionary note at this stage. In advocating the use of ignorance in argument, I am not suggesting that people should actively avoid acquiring knowledge about the many different things they experience in their lives. My stance is not a call to reject education and learning, and to live in a state of self-imposed ignorance. It is quite the opposite, in fact. The use of ignorance in argument is proposed as a means of increasing our knowledge. There is no contradiction between advocating that we use ignorance during reasoning and recommending that we undertake efforts to eradicate ignorance through education and learning. Accepting one of these positions does not require that we reject the other position. If we think for a moment about health, the serious consequences of ignorance can be very clearly demonstrated. We saw earlier that ignorance can expose us to risk from infectious diseases like HIV and hepatitis. It can also lead us to adopt lifestyles that damage our health, and prevent us from engaging with health checks and screening programs (e.g. bowel cancer screening). Indicators of ignorance about 
health are easy to find. Jalloh et al. (2017) interviewed 1413 randomly selected respondents from 9 out of 14 districts in Sierra Leone about their knowledge of Ebola three months into the 2014 outbreak. Only $42 \%$ of respondents linked Ebola to a virus. A further $41 \%$ falsely believed that they could protect themselves from Ebola by washing with salt and hot water, while $30 \%$ expressed the mistaken view that Ebola is transmitted by air (• Fig. 2.3).

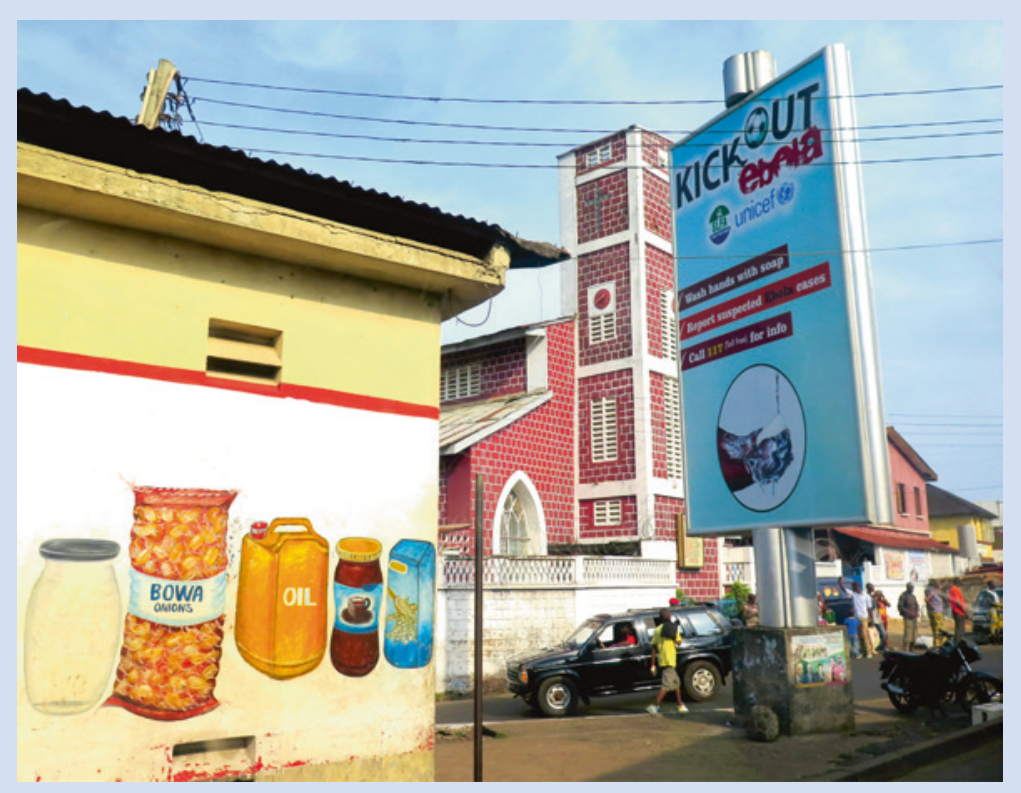

- Fig. 2.3 A street scene in the capital city of Freetown, Sierra Leone, during the 2014 West African Ebola virus outbreak. The 'Kick Out Ebola' message was used to raise awareness of the disease (Photo by Angela J. Sanchez, M.S., M.T. is reproduced courtesy of CDC)

Some $26 \%$ of Jalloh et al.'s respondents had no formal education. However, even in better educated subjects, there are still high levels of ignorance about matters related to health. Between February and April 2008, Inungu et al. (2009) examined knowledge of HIV/AIDS in 650 students enrolled at a Midwestern University in the United States. Although $98.2 \%$ of respondents knew that the chances of contracting HIV/AIDS were reduced by having only one partner who was not infected, and by using condoms consistently during sex, 19.9\% did not know if mosquitoes transmitted HIV/AIDS. A further $14.4 \%$ thought that mosquitoes did represent a route of transmission. Even in individuals who were receiving tertiary-level education, gaps in knowledge about this prominent infectious disease were still very much in evidence. 


\subsection{Logic and Ignorance}

We have already seen that not every appeal to ignorance in argument is rationally warranted. If I tell you that the Dublin train does not stop in Newry because I found no evidence when I examined the timetable that Newry is one of the stops, then you may be reasonably confident in concluding that the train does not stop in Newry. However, imagine for one moment that you discover I was consulting an old timetable or a timetable that had a few pages missing. Would you be so inclined under these conditions to accept my claim that the Dublin train does not stop in Newry? Of course you would not. That is because you would have discovered circumstances that lead you to doubt that the knowledge base upon which I am basing my claim is complete. If I am consulting an old timetable, the route the train takes may have been altered so as to include Newry as one of the stops on the journey. If one of the missing pages lists some of the stops that the Dublin train makes, then Newry could conceivably be one of the stops on a missing page. In both scenarios, you have discovered something that leads you to query if the closed world assumption holds in this particular case. This assumption can be stated as follows:

\section{- Closed world assumption:}

An assumption to the effect that all information that is relevant to a particular domain $D$ is contained in a knowledge base $K$.

In our example above, we tend to doubt that all information that relates to the train journey between Belfast and Dublin (domain $D$ ) can be contained in knowledge base $K$, represented here by the timetable, when we discover that the timetable is old or that the copy I am consulting has missing pages. This simple example of how the closed world assumption can fail to hold in a particular case powerfully illustrates that there are certain conditions on the use of ignorance in argument. Not just any absence of knowledge or evidence can provide logical grounds for a conclusion. Moreover, the conditions under which the closed world assumption may not be presumed to hold are as numerous as the different types of knowledge bases at the centre of this assumption. On some occasions, there may be information that is relevant to a particular domain $D$ but that cannot be contained in our knowledge base $K$ because inadequate time has elapsed for this to occur. Just such a scenario arose in the 1980s during the BSE epidemic in the UK, when the public was encouraged to continue eating beef and beef products because there was no evidence that BSE transmitted to humans. It was known at the time that BSE was a spongiform encephalopathy and, as such, would have a lengthy incubation period. It would take many years before scientists would know if BSE could transmit to humans. Certainly, the absence of evidence of BSE transmission to humans in the early months of the epidemic could not be used as grounds on which to conclude that BSE does not transmit to humans. The closed world assumption did not hold in this case because information about the transmission properties of BSE was not present in our knowledge base about this new disease, and could not possibly be present in the early months following the emergence of BSE. 
So the closed world assumption does not hold in the case where there has been inadequate time for investigators to establish if a proposition $P$ is the case. This raises the question of what constitutes adequate time. For a disease like BSE with a lengthy incubation period, the passage of just a few months was certainly inadequate. But this judgement becomes more difficult to make as we encounter longer periods of time. Would we also be inclined to describe 10 years or 20 years as inadequate? Would the failure of BSE to transmit to humans after 30 years be sufficient grounds on which to conclude that BSE does not transmit to humans? We are beginning to see some of the complex judgements that arguers must make as they attempt to evaluate the rational merits of different arguments. Moreover, time is not the only condition that may affect whether the closed world assumption holds in a particular case. If investigators have not had at their disposal the resources that are required to establish if a certain proposition $P$ is true, then we can conclude nothing at all from the fact that there is no evidence that $P$. Imagine the proposition that we are interested in is the claim that restaurant workers in a certain large city are carriers of hepatitis A. However, due to budget cuts, there is a lack of trained staff to take blood samples from restaurant workers and to test these samples for the presence of hepatitis A in the laboratory. We certainly could not say under such circumstances that the lack of evidence that there are restaurant workers who are carriers of hepatitis A leads us to conclude that such workers do not exist. The closed world assumption does not hold in this case because investigators have been constrained by budget cuts from adding any information about the hepatitis A status of restaurant workers to the knowledge base $K$.

When trying to establish if the closed world assumption holds in a particular case, there are linguistic markers that arguers can use to assist them. For example, if we are told that a particular pesticide has been in extensive use for the last 50 years and there is no evidence that it has caused ill health in humans, then we can be reasonably certain that it does not cause ill health in humans. The two markers that lead us to believe that the closed world assumption obtains in this case are the fact that the pesticide has been in extensive use and that it has been in use for 50 years. The former marker-we will call it the dose marker-lets an arguer see that there has been widespread exposure of humans to the pesticide in question. The latter marker-we will call it the temporal marker-lets an arguer see that a sufficient period of time has elapsed in which adverse health effects, if they were to occur, would have become evident. Other linguistic markers capture the size of an investigation and the expertise of investigators. Imagine for a moment that you are told that 10,000 restaurant workers in New York are tested for hepatitis $\mathrm{A}$ in an epidemiological investigation that is conducted by public health experts in the city's health department, and there was no evidence that restaurant workers are carriers of hepatitis A. Then you would feel reasonably certain in concluding that restaurant workers are not carriers of hepatitis A. In this case, the two markers that are the basis of your certainty are the fact that there has been a large investigation-10,000 restaurant workers were tested-and that the investigators had the requisite expertise to conduct the investigation. We will call the former marker the scope marker, and the latter marker the expertise marker. These markers may occur singly or in combination. They can each influence positively and negatively the extent to which the closed world assumption may be presumed to hold in a particular case. 


\section{EXERCISE 2.1: Closed world assumption}

We have seen that a number of linguistic markers may be used by arguers to determine if the closed world assumption holds in a particular case. We called these markers dose, temporal, scope and expertise markers. The following statements are taken from the press releases of a number of public health agencies. Imagine that each of these statements exists in the background of an argument from ignorance. For each statement, indicate the type of markers that may be used by arguers to decide if the closed world assumption is warranted in a particular case.

(A) The Department of Health, Australia, 3 April 2017

I) Perfluoroalkyated substances have been used since the 1950s in industrial processes, in a range of common household products, and some types of firefighting foams. (Press release: Australian guidance values for assessing exposure to perfluorooctane sulfonate (PFOS) and perfluorooctanoic acid (PFOA))

(B) Centers for Disease Control and Prevention (CDC), USA, 25 January 2018

॥ CDC looked at nearly 1 million births in 2016 in 15 U.S. states and territories [...] About three out of every 1000 babies born in 15 states and territories in 2016 had a birth defect possibly associated with Zika virus infections in the mother. (Press release: More birth defects seen in parts of U.S. with local Zika spread)

(C) Public Health England, UK, 3 August 2017

I) Public Health England (PHE) has run a surveillance system with partners since 2010. This now includes surveillance at more than 30 UK sea and airports and at the largest used tyre importers. Since invasive mosquitoes have become more widespread in France, surveillance has been conducted by PHE at motorway service stations in the south east of England on the main routes from the south coast ferry ports and Eurotunnel (since 2014). The surveillance system combines a number of traps that detect mosquito eggs, host-seeking and blood-fed mosquitoes and larval sampling. (Press release: Mosquito treatment in Ashford, Kent)

Where the closed world assumption holds in a particular case, it can increase the rational warrant of the conclusion of an argument that is based on ignorance. But another condition must also be fulfilled for ignorance to have proper logical standing in an argument. We have been calling that condition the extensive search criterion. This criterion can be stated as follows:

- Extensive search criterion:

The search of a knowledge base $K$ is conducted to the fullest extent possible, using every reasonable means available. 
A knowledge base $K$ can be complete in the sense of containing all relevant information in a particular domain $D$. However, if the base is not extensively examined, then little logical weight can be attached to any ignorance claim that is based upon it. Imagine that a knowledge base contains the blood test results of the 10,000 restaurant workers in New York who were tested for hepatitis A in the above scenario. However, the scientists who are reviewing the results from the epidemiological study decide to examine only 2500 blood test results from restaurant workers who are employed at establishments in the north of the city. We would be very much disinclined to accept any claim based on what was not found during such a limited search of the knowledge base. By the same token, we would also be unlikely to accept a claim based on a search of the knowledge base, even a very extensive search of the knowledge base, if that search were conducted by non-expert reviewers. Even medically qualified or scientifically trained individuals may not have the requisite expertise to assess the epidemiological implications of a large number of blood test results for hepatitis A. So while we are prepared to accept the verdict of a panel of infectious disease epidemiologists who have conducted an extensive review of the knowledge base, we are much less likely to do so if we are told that gastroenterologists or astrophysicists undertook the review. The judgements that are required to decide if the extensive search criterion is satisfied in a particular case are no less complex than those needed to determine if the closed world assumption holds in a certain context. But as with the closed world assumption, there are linguistic markers that can guide us in making these judgements.

To get a sense of what these markers look like, we return to the BSE epidemic that occurred in the UK. Shortly after the first cases of BSE emerged in British cattle, a group of investigators published a significant article in the journal Neurology. The article concerned a spongiform encephalopathy in sheep called scrapie. The question of interest to the investigators, Brown et al. (1987), was whether there was any epidemiological evidence to suggest that scrapie had transmitted to humans. Brown et al. concluded that there was no evidence that scrapie in sheep had transmitted to humans. The basis of their ignorance claim was a review of the world literature on CJD as well as an examination of the results of a 15-year epidemiological study of CJD and scrapie in France. In other words, the available evidence was very extensively examined by Brown and his colleagues. Moreover, these investigators were expertly qualified to make an assessment of the evidence. The lead author, Paul Brown, and two of his co-authors were based at the Laboratory of Central Nervous System Studies at the U.S. National Institutes of Health in Bethesda, Maryland. A further co-author, Richard Raubertas, was affiliated with the Division of Biostatistics at the University of Rochester Medical Centre in New York. We will call these features the comprehensiveness marker and the expertise marker, respectively. A search of a mundane knowledge base, such as the journeys in a train timetable, does not need to be undertaken by experts. In this case, an expertise marker may be superseded by a competence marker-the individual who is examining the timetable is presumed to have a certain minimum level of competence. Alone or in combination, these markers can influence our assessment of whether the extensive search criterion is satisfied in a particular case. 


\section{EXERCISE 2.2: Extensive search criterion}

To give you practice at identifying linguistic markers related to the extensive search criterion, you should examine the following statements. They are taken from press releases from a number of public health agencies around the world. Each statement describes an investigation. You should identify key features of the investigation using terms such as expertise marker and comprehensiveness marker:

(A) The Department of Health, Australia, 26 February 2015

I) As each case was notified they were investigated by state health authorities in Victoria like all cases of Hepatitis A [...] after investigation of cases and detailed analyses of food consumption histories, the Victorian authorities confirmed a possible association with frozen berries on Thursday 12 February 2015. (Media statement: Hepatitis A linked to frozen berries)

(B) Department of Health, Hong Kong, 2 April 2010

I) The Centre for Health Protection (CHP) of the Department of Health today received notification from the Queen Elizabeth Hospital about a 70-year-old man presenting with neurological symptoms and history of human swine influenza (HSI) vaccination. A CHP spokesman said "CHP will closely monitor the clinical progress and further laboratory results of the patient. Information about the case will be reviewed by the Expert Group in due course for determination of diagnosis and etiology". The Expert Group has earlier reviewed Guillain-Barré syndrome (GBS) cases with HSI vaccination history and concluded that no causal relationship could be established on the basis of the observed GBS incidence. (Press release: Centre for Health Protection investigates a patient with lower limb symptoms and history of human swine influenza vaccination)

(C) Department of Health, South Africa, 5 December 2017

I) In July 2017 doctors from neonatal units in Chris Hani Baragwanath and Steve Biko Academic hospitals alerted the National Institute for Communicable Diseases (NICD) about an unusually high number of babies with listeriosis. This triggered a review by NICD of all cases diagnosed in both public and private hospitals. (Media statement: Minister of Health, Dr Aaron Motsoaledi, on the outbreak of listeriosis in South Africa)

This section has demonstrated that when employed under certain conditions, ignorance can have logical standing in an argument. Those conditions are represented by the closed world assumption and the extensive search criterion. Of course, whether or not an argument fulfils these conditions in a particular case is a task for the argument analyst. In the context of medicine and health, the argument analyst could be each one of us-the parent who is deciding whether or not to vaccinate a child, the doctor who wants to recommend a course of treatment to a patient, or the public health official who is issuing advice on how to limit the transmission of an infectious disease. For each of us must evaluate the logical role of ignorance in argument in deliberations 
about our own health and the health of others. In the next section, we examine a number of ignorance arguments used in medical and health contexts. We will see that conditions such as the closed world assumption and extensive search criterion are not always fulfilled in these contexts.

\section{SPECIAL TOPIC: 'No evidence' statements in systematic reviews}

One context in which 'no evidence' statements are used extensively in medicine and health is in the conclusions of systematic reviews. When we consider what these reviews involve, it is not difficult to see why this is the case. A systematic review is a review of all research studies and their findings relating to a particular question. In undertaking such a review, investigators aim to identify all studies in an area, select those studies that satisfy certain criteria for inclusion in the review, assess the quality of the studies and the evidence that they produce, synthesise their findings, and arrive at a balanced interpretation of their significance. Upon completion of a systematic review, a knowledge base may be said to be closed (at least at a particular point in time) and extensively searched. A 'no evidence' statement is then used to characterise any proposition that is not contained in the knowledge base.

The issue that concerns us is whether a systematic review can be used to transform a 'no evidence' statement into the premise in a strongly warranted argument from ignorance. On some occasions, a systematic review appears to do just that. Where a review has included only the most rigorously conducted studies that produce high-quality evidence, then there are very strong grounds for drawing a conclusion based on an absence of evidence. Such studies are typically randomized controlled trials (RCTs) like those referred to by Pennington et al. (2016) in the conclusion of a systematic review of the use of speech and language therapy (SLT) to treat children with dysarthria (a motor speech disorder) that is acquired before three years of age:

I) This review found no evidence from randomised trials of the effectiveness of speech and language therapy interventions to improve the speech of children with early acquired dysarthria.

The 'no evidence' statement in the conclusion to this review can be used as a premise in a strongly warranted argument from ignorance:

Strongly warranted argument from ignorance:

There is no evidence that SLT is effective in the treatment of children with early acquired dysarthria.

Therefore, SLT is not effective in the treatment of children with early acquired dysarthria.

A RCT produces high-quality evidence. A systematic review of other types of studies can also give rise to 'no evidence' statements. However, to the extent that these statements are based on reviews of studies other than RCTs, they may provide weaker warrant in an argument from ignorance. Tsoumanis et al. (2018) conducted 
a systematic review of uncontrolled observational studies of the prevalence of chlamydia and gonorrhoea in men who have sex with men (MSM). This systematic review concluded that there was an absence of evidence that screening of MSM for chlamydia and gonorrhoea achieved a lowering of the prevalence of these infections:

I) Our study was not able to provide evidence that screening for chlamydia and gonorrhoea lowers the prevalence of these infections in men who have sex with men.

This conclusion can certainly provide some rational warrant for the claim that screening does not achieve a lowering of prevalence of chlamydia and gonorrhoea in MSM. But this rational warrant is altogether weaker than the rational warrant in our first example, on account of the fact that it is based on a systematic review of observational studies and not RCTs:

Weakly warranted argument from ignorance:

There is an absence of evidence that screening for chlamydia and gonorrhoea lowers the prevalence of these infections in MSM.

Screening for chlamydia and gonorrhoea does not lower the prevalence of these infections in MSM.

Variants of these 'no evidence' statements are also commonly used in the conclusions of systematic reviews. Sometimes, the evidence that is lacking from the knowledge base is described as 'strong' or 'significant'. This implies that there is evidence available but that it is weak or insignificant. It would be an interesting empirical question to consider if the addition of these adjectives to the noun 'evidence' has the effect of deterring an arguer from drawing an inference based on ignorance. In this way, an arguer may reason that there is some (weak) evidence that $p$ and that it cannot therefore be concluded that not- $p$. These variants are illustrated by the following examples. In the first example, the 'no evidence' claim relates to the effectiveness of non-speech oral motor treatments in the management of children with developmental speech sound disorders:

I) Currently no strong evidence suggests that non-speech oral motor treatments are an effective treatment or an effective adjunctive treatment for children with developmental speech sound disorders. (Lee and Gibbon 2015)

In the second example, the absence of evidence relates to the effectiveness of dysphagia interventions (swallowing treatments) in the management of clients with hereditary ataxia:

ע) There is an absence of any significant evidence supporting the use of dysphagia intervention in hereditary ataxia. (Vogel et al. 2015)

These 'no evidence' and 'absence of evidence' statements appear to provide the weakest basis of all the statements that we have examined for a conclusion based on ignorance. For while there is some evidence that $p$, even some weak evidence that $p$, there appears to be little rational warrant for drawing the conclusion that not- $p$. 


\section{$\checkmark$ DISCUSSION POINT: Systematic reviews in academic journals}

In an article in the British Medical Journal, Alderson and Roberts (2000) pose the question: 'Should journals publish systematic reviews that find no evidence to guide practice?' The authors argue that journals should make a point of publishing such reviews rather than waiting for reviews that show marked benefit or harm. However, some experts disagree, arguing that inconclusive systematic reviews simply reinforce the message that there is clinical uncertainty. What do you think journals should do with systematic reviews that report no evidence?

\subsection{Arguing from Ignorance in Medicine and Health}

We have already seen some of the ways in which ignorance can be used to positive and negative effect in argument. If I argue that proposition $p$ is not the case because there is no evidence that $p$ is the case, and I have based my 'no evidence' claim on a closed knowledge base that has been extensively searched, then I have very strong grounds indeed for claiming that not- $p$ is true. This was effectively the position of Brown and his colleagues in 1987 when they argued that scrapie does not transmit to humans because there was no evidence based on a review of the world literature and a 15-year epidemiological study that scrapie transmits to humans. But very often in medicine and health, arguments from ignorance can go badly awry. In these cases, we do not have a rationally warranted claim that we can use in reasoning and decision-making, but an unwarranted, possibly false claim that gets us nowhere at all. When a knowledge base is closed prematurely, as it was in the case of the BSE epidemic in the UK, we can base almost nothing at all on ignorance. The claim that BSE does not transmit to humans because there was no evidence that it had transmitted to humans was not only rationally unwarranted when it was advanced, but has since also been tragically shown to be false. Also, when a knowledge base, even a complete knowledge base, is only partially examined, we can base nothing at all on a claim that a particular proposition is not in the base. Ignorance achieves nothing for us if a search of a base has been incomplete, or has not been competently or expertly conducted. In this section, we will see how arguers in medical and health contexts navigate these conditions on the logical use of ignorance in argument.

Consider the following extract from a press release on 25 March 2014 from Public Health England (PHE). The extract describes the findings of a report by PHE into the health effects of water fluoridation schemes:

I) Children in local authorities with water fluoridation schemes have less tooth decay than those in local authorities without such schemes, says a new report by Public Health England (PHE). The report says there is no evidence of harm to health in fluoridated areas. PHE has found no differences between fluoridated and nonfluoridated areas in their rates of hip fracture, osteosarcoma (a form of bone cancer), cancers overall, Down's syndrome births or all-cause mortality (all recorded causes of death). (Press release: Fluoride monitoring report finds lower levels of tooth decay in fluoridated areas and no evidence of harm to health) 
Imagine that you are the parent of a young child and that you live in a water fluoridation area. You have had concerns for some time about the potential health effects of fluoridation. You have read stories online and in the local newspaper about this issue, and have also discussed it with some of your friends. You hear on the television that Public Health England has published a significant report on the issue. You head to the PHE website where you read the above press release. You have no scientific or technical expertise to draw on, and you certainly do not believe you have the knowledge to read and understand the full report. So you try to make the best assessment possible of the findings of the report based on the press release from PHE. You feel reasonably convinced on the basis of the press statement that water fluoridation does not cause ill health effects in humans. Three factors lead you to this conclusion. The first factor is the finding of lower levels of tooth decay in children who live in local authorities that have water fluoridation schemes. This positive finding suggests that there are health benefits to be derived from fluoridation. The second factor is the finding that a number of cancers, congenital disorders, and other conditions do not have an elevated prevalence in fluoridated areas. The logical pull of these factors is clearly in the direction of the conclusion that fluoridation does not cause ill health effects. The third factor is the use of a 'no evidence' statement. When interpreted against the backdrop of the rest of the PHE press release, and particularly the logical pull of the first two factors, this statement leads you to reason along the following lines:

There is no evidence that water fluoridation causes harm to humans.

Therefore, water fluoridation does not cause harm to humans.

You believe the conclusion of this argument from ignorance is rationally warranted given some additional information that PHE has included in its press release. This information conveys two key facts about fluoridation that were not previously part of your knowledge:

I) Currently, around 6 million people live in areas with fluoridation schemes. Many schemes have been in operation for over 40 years.

These facts provide the rational warrant you need to support the closed world assumption at the heart of your argument from ignorance. The fact that around 6 million people have been exposed to fluoridation is an important dose marker that gives you confidence that the knowledge base on the health effects of fluoridation may be assumed to be closed. Also, the fact that many fluoridation schemes have been in operation for over 40 years is an important temporal marker that the knowledge base may be treated as closed. The closed world assumption appears strongly warranted to you in this particular case on the basis of these two markers. Your attention then turns to the extensive search criterion. You want to determine if this is as strongly warranted as the closed world assumption. Additional information in the press release once again helps you make a decision. The press release from PHE states that this is the first report on the health of people living in fluoridated areas since PHE came into existence in April 2013. However, you have sufficient trust in the expertise of this body to conclude that the authors of the report will have conducted the fullest review possible 
of all the available evidence on the health effects of fluoridation. So you use an expertise marker as rational warrant for the extensive search criterion. With both the closed world assumption and the extensive search criterion strongly warranted in this case, you feel there is sufficient rational justification to draw the conclusion of the above argument from ignorance. You come away from reading the PHE press release with the firm belief that water fluoridation does not cause harm to humans.

This scenario has all the hallmarks of a rationally warranted use of the argument from ignorance. First, the argument does not stand alone as the sole means of rational persuasion of readers. Rather, the conclusion of the argument from ignorance-fluoridation does not cause harm to humans-is also supported by two other findings that are independent of the argument from ignorance. These are the findings of reduced levels of tooth decay in children who live in fluoridated areas, and similar prevalence of cancers and congenital disorders in fluoridated and non-fluoridated areas. Second, PHE provides sufficient background information for readers to determine if the two conditions on the rationally warranted use of the argument from ignorance-the closed world assumption and the extensive search criterion-hold in this particular case. The press release clearly indicates for readers that a large number of people have been exposed to fluoridation over a period of at least 40 years. Readers can readily identify a dose marker and a temporal marker in this information, which may be used to support the closed world assumption. That PHE is a reputable body of public health experts provides readers with an expertise marker that they can use to support the extensive search criterion. Third, although this is the first water fluoridation report that PHE has produced since it came into existence in April 2013, the Chief Knowledge Officer at PHE, Professor John Newton, is reported in the press release to have said that PHE is required by legislation to produce a similar report every four years. This information recognizes the possibility that new evidence may be forthcoming in the future. This evidence may substantially change the knowledge base that is the basis of our current conclusion that fluoridation does not cause harm to humans. The PHE press release acknowledges that this conclusion, like the conclusion of any ignorance argument, is defeasible in the presence of contrary evidence. A less responsible form of public health communication may not have countenanced the possibility of such revision.

This last point is sufficiently important to warrant further discussion. Any claim based on an argument from ignorance is defeasible in the sense that it can be overturned if contrary evidence emerges at some later point in time. In the above scenario, that possibility is explicitly signalled by Professor John Newton when he states that there will be continuous monitoring of the human health effects of fluoridation in subsequent reports by PHE. But very often, the defeasible nature of a claim that is based on ignorance can be indicated through the use of language rather than by the provision of additional information as in this particular case. There are linguistic markers of defeasibility in the same way that there are linguistic markers of a closed knowledge base and an extensively searched knowledge base. To illustrate some of these markers, consider the following 'no evidence' statements in press releases from the Department of Health in Hong Kong: 
I) No scientific evidence to date has confirmed a link between Zika virus and microcephaly or Guillain-Barré syndrome. (Press release on 15 February 2016: Centre for Health Protection closely monitors latest WHO Zika epidemiological updates)

I) 'It is also safe to eat pork, provided it is well-cooked. At present, there is no evidence that Hong Kong is at high risk of an outbreak. However, we will continue to monitor closely the situation as well as the latest developments in Sichuan', said Dr York Chow, the Secretary for Health, Welfare and Food. (Press release on 1 August 2005: Streptococcus suis to become notifiable disease)

The underlined temporal markers in these statements indicate that the emergence of new evidence may necessitate a revision of the knowledge base upon which these 'no evidence' claims are based. In some cases, these markers may have the effect of dissuading a reader from drawing an inference based on ignorance altogether. But in those cases where an inference is drawn based on the absence of evidence, these markers provide a note of caution to the effect 'Reader beware, what holds now may be overturned at a later point in time'. In drawing the reader's attention to the defeasibility of a claim that is based on the absence of evidence, these temporal markers are doing important logical work. Like the other markers we have examined, they are highlighting the epistemic conditions that are integral to the rationality of the argument from ignorance.

\section{EXERCISE 2.3: Defeasibility of the argument from ignorance}

We have seen that there are linguistic markers of defeasibility in the same way that there are linguistic markers of other logical features of the argument from ignorance. The following 'no evidence' statements are taken from press releases of three public health agencies, Public Health England and the Department of Health and Social Care in the UK, and the Department of Health in Hong Kong. For each statement, identify a temporal marker that suggests the defeasibility of claims that are based on an absence of evidence:

(a) Department of Health, Hong Kong, 10 June 2016

I) 'We have no evidence at this stage that patients of the five recent cases so far had received injections in the same premises. Epidemiological investigations are ongoing', a spokesman for the Department of Health said. (Press release: Centre for Health Protection investigates additional case of suspected botulism following botulinum toxin injections)

(b) Department of Health and Social Care, UK, 23 December 2011

॥ Chief Medical Officer Dame Sally Davies said: 'While we respect the French Government's decision, no other country is taking similar steps because we currently have no evidence to support it. Because of this, and because removing these implants carries risk in itself, we are not advising routine removal of these implants.' (Press release: Chief Medical Officer statement on breast implants) 
(c) Public Health England, UK, 26 November 2015

॥ A range of surveillance indicators are used to measure flu activity in the UK. At the moment these remain low across the UK, suggesting there is presently no evidence of community transmission of influenza. (Press release: Improved vaccine uptake for children, pregnant women and older people)

(d) Department of Health, Hong Kong, 18 January 2010

I) In response to media enquiries concerning a 66-year-old woman with a history of human swine influenza (HSI) vaccination who passed away yesterday, a spokesman for the Centre for Health Protection of the Department of Health said that as clarified with the hospital, 'So far, no evidence shows that the death was related to HSI vaccination'. (Press release: No evidence suggests linkage of fatal case with human swine influenza vaccination)

(e) Public Health England, UK, 11 February 2015

I) Dr Dipiti Patel, joint director at the National Travel Health Network and Centre, said: 'Birds can carry a wide variety of avian flu viruses and most of these do not cause human illness. The two types of avian flu viruses currently causing the greatest concern for human health are H5N1 and H7N9. These infections are typically seen in people who have had close contact with birds. To date there has been no evidence of sustained human-to-human spread of avian flu viruses.' (Press release: Travel safely this Chinese New Year)

The 'fluoridation' argument is an example of the rationally warranted use of ignorance in extended argumentation. Moreover, Public Health England directly engaged the rational resources of readers by providing the type of information that could achieve closure of the knowledge base at the heart of the argument. This is an example of public health communication that was responsibly conducted and rationally warranted. Instances of the sound or rationally warranted use of the argument from ignorance are, however, quite rare in medical and health contexts. Fallacious arguments from ignorance are relatively common in these contexts. In the remainder of this section, an equally detailed analysis will be conducted of the fallacious use of the argument from ignorance in public health. The issue on this occasion concerns the safety of Poly Implant Prothèse (PIP) breast implants following an announcement on 23 December 2011 that the French Government was recommending women to have these implants removed as a precautionary, but non-urgent measure. Recognizing that this announcement would cause widespread concern among the thousands of British women who had also received PIP implants, the Chief Medical Officer, Professor Dame Sally Davies, released a press statement to the public and wrote a letter to general practitioners, Medical Directors in the National Health Service (NHS), and cancer and plastic surgeons. The press release and letter, which were issued by the Department of Health in the UK on the same day as the French Government's announcement, made extensive use of 'no evidence' statements. Two examples of these statements are shown below: 
I) Chief Medical Officer Dame Sally Davies said: 'Women with PIP implants should not be unduly worried. We have no evidence of a link to cancer or an increased risk of rupture. If women are concerned they should speak to their surgeon.' (Press statement: Chief Medical Officer statement on breast implants)

I) In the UK, the Medicines and Healthcare products Regulatory Agency (MHRA) is not $[. .$.$] recommending routine removal because they have no evidence of any$ disproportionate rate of implant rupture. Moreover, there is no evidence of any increase in incidence of cancer associated with these implants. (Letter to NHS staff: PIP silicone gel breast implants)

The Chief Medical Officer used 'no evidence' statements on six occasions in these communications to the public and to staff in the NHS. The thrust of these statements was clear. The public and medical professionals alike were being strongly encouraged to draw the conclusions that PIP implants are not associated with a disproportionate rate of implant rupture, and are not associated with an increase in incidence of cancer. These were undoubtedly reassuring messages for women with these implants to be given. The question that concerns us is whether the claims at the centre of these messages are rationally warranted. These claims are derived by means of the following arguments from ignorance:

There is no evidence that PIP implants have a disproportionate rate of implant rupture.

PIP implants do not have a disproportionate rate of implant rupture.

There is no evidence that PIP implants are linked with an increase in incidence of cancer. PIP implants are not linked with an increase in incidence of cancer.

As with the 'fluoridation' argument, we need to establish if there are grounds for presuming that the closed world assumption and the extensive search criterion hold in this case. The closed world assumption looks decidedly weak on this occasion. The Chief Medical Officer made her remarks on 23 December 2011. This was some six months before the expert group that was tasked with examining the safety of PIP implants produced its final report on 18 June 2012. This group was chaired by Sir Bruce Keogh, NHS Medical Director. An interim report was produced by Sir Bruce and his colleagues on 6 January 2012. However, even the findings of the interim report were not available to the Chief Medical Officer when she embarked on providing reassurance to the public about the safety of PIP implants on 23 December 2011. The haste with which reassurance was offered about the safety of PIP implants was later found to be misguided. In its final report, the expert group chaired by Sir Bruce concluded:

I) PIP implants are significantly more likely to rupture or leak silicone than other implants, by a factor of around 2-6. (Keogh 2012: 1)

The Chief Medical Officer did not have access to the interim or final reports of the expert group at the point when she was using 'no evidence' statements to provide reassurances about the safety of PIP implants to the public. These reports, particularly 
the final report, would have been strong grounds to suppose that the closed world assumption was warranted in this case. But in the absence of these reports, the Chief Medical Officer was basing her 'no evidence' statements on a very limited knowledge base indeed. Clearly, there would be no evidence of any rupture risk or cancer risk associated with these implants in advance of the inquiry that was supposed to establish if these risks existed. Of course, the Chief Medical Officer was basing her 'no evidence' statements on some grounds. She set out what these grounds were, both in her press statement and in her letter to key NHS staff on 23 December 2011:

॥ The Medicines and Healthcare products Regulatory Agency (MHRA) has previously commissioned toxicity testing on the filler, including genotoxicity and chemical toxicity, discussed this with their experts and concluded that there is no associated safety issue. The MHRA have also reviewed available evidence for association of cancers of women with breast implants in consultation with the relevant UK professional bodies for breast surgery and surgical oncology and with the Cancer Registry, and have concluded there is no evidence to indicate any association. (Letter to NHS staff: PIP silicone gel breast implants)

The MHRA regulates medicines, medical devices and blood components for transfusion in the UK. On 29 March 2010, the French medical device regulatory authorityAgence Française de Sécurité Sanitaire des Produits de Santé (AFSSAPS)-informed MHRA that it had suspended the marketing, distribution, export, and use of PIP implants following an inspection of the PIP manufacturing plant. AFSSAPS had established that breast implants manufactured since 2001 had been filled with a silicone gel with a composition different from that which had been approved. In April 2010, AFSSAPS initiated testing of affected implants to look at genotoxicity (potential for cancer), cellular toxicity and irritation to biological tissues. At the end of June 2010, AFSSAPS told the MHRA of delays to their product testing. At that point, the MHRA decided to commission a specific series of tests (the Ames tests) to measure the genotoxic activity of chemicals in PIP silicone. These are the tests that the Chief Medical Officer describes in her letter to NHS staff. The results of these tests were uniformly negative. However, these tests and their results really tell us nothing at all about the claims that are central to the Chief Medical Officer's 'no evidence' statements. It will be recalled that one of those claims concerns the rate of rupture of PIP implants relative to other types of implants. No amount of genotoxicity and chemical toxicity testing could address this concern. This issue could only be addressed by the investigation led by Sir Bruce Keogh as part of the work of his expert group.

As a result of the urgency to provide public reassurance about the safety of PIP implants, the Chief Medical Officer made fallacious use of the argument from ignorance. Her repeated use of 'no evidence' statements suggested that a closed knowledge base was already available to investigators when this was in fact not the case. Toxicity tests of PIP silicone certainly contributed important information to the knowledge base. But these tests could not address questions about the rupture rates of PIP implants that were at the heart of the messages of reassurance offered by the Chief Medical Officer. Answers to these questions awaited the final report of the expert group led by Sir Bruce Keogh. However, this group did not publish its report until 18 June 2012, some six months after the advice given to the public and medical 
professionals by Professor Dame Sally Davies. This advice was misleading and, on the question of PIP implant rupture rates, was shown ultimately to be inaccurate. The argument from ignorance was 'overplayed' by the Chief Medical Officer in an effort to reassure PIP implant recipients in the UK that there was no need to adopt the precautionary approach taken by French authorities. There was no closed knowledge base or extensively searched knowledge base, as the Chief Medical Officer's statements appeared to suggest. Both awaited the findings of the investigation conducted by Sir Bruce Keogh's expert group. The knowledge base on PIP implant safety did contain information about the toxicity of chemicals in PIP silicone. But this information was erroneously used by the Chief Medical Officer to force the closure of the knowledge base, and draw a reassuring conclusion about PIP implant safety based on the absence of any evidence relating to the rupture of implants (• Fig. 2.4).

It has taken considerable work to expose the fallacious argument from ignorance at the centre of the Chief Medical Officer's claims. The knowledge base on PIP implant safety has been subjected to extensive scrutiny. This has necessitated an examination of the type of information that was contributed to the base, as well as an assessment of how and when this information was obtained, and whether it relates to the claims advanced by the Chief Medical Officer. Needless to say, this level of scrutiny exceeds the interest and intellectual curiosity of most members of the public, perhaps even most PIP implant recipients. This is exactly why fallacious uses of the argument from ignorance are so dangerous. They can easily strike us as a persuasive form of argument when further analysis reveals that they are anything but rationally warranted. Some logical protection is afforded if we keep the closed world assumption and extensive

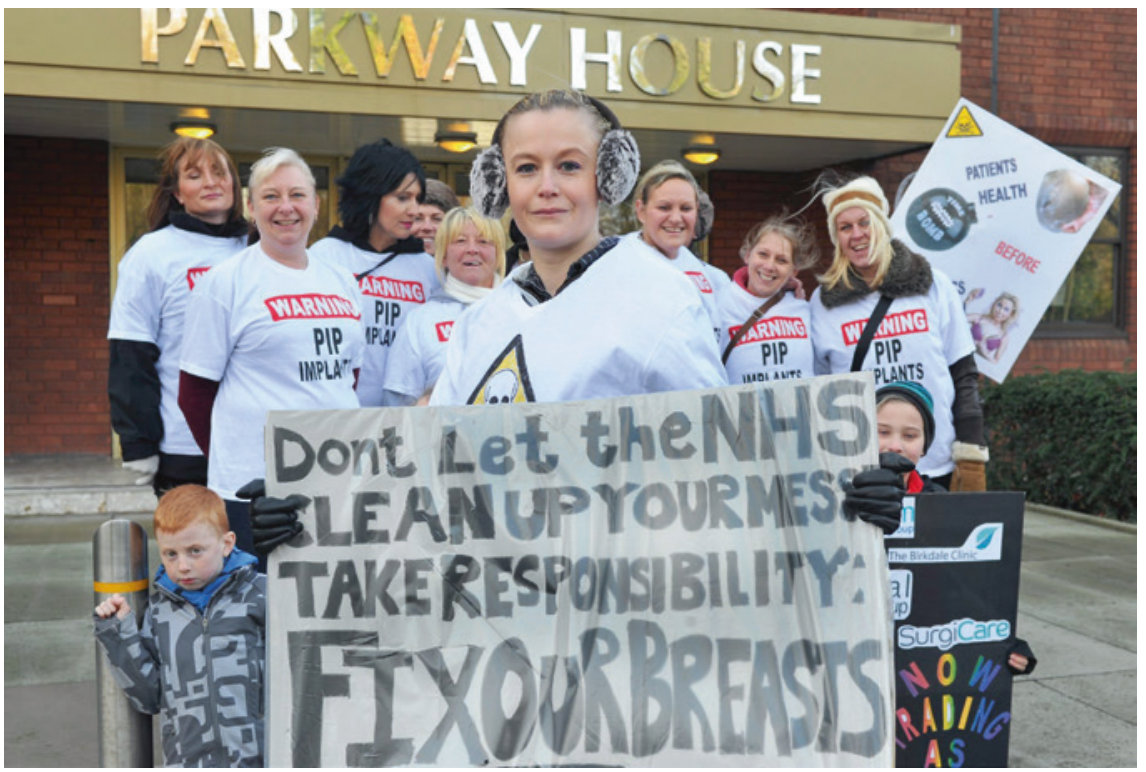

- Fig. 2.4 Protest at Surgicare Medical Group clinic in Northenden, south Manchester, by women with faulty PIP breast implants including Laura Costello (centre, front), January 22, 2012 (Reproduced with kind permission of MEN Media) 
search criterion at the centre of our attention. In this case, it became apparent quite quickly that the Chief Medical Officer was overstating the closure of the knowledge base on PIP implant safety. Repeated use of 'no evidence' statements did little to disguise the fact that the knowledge base lacked information relating to the rupture rates of PIP implants. And the results of toxicity tests, which did form part of the knowledge base, were unable to address this critical aspect of PIP implant safety. Alongside the overuse of 'no evidence' statements, another feature of this scenario that should have alerted us to a potentially fallacious use of the argument from ignorance was the timing of the Chief Medical Officer's statements. These statements were a hasty reaction to the precautionary measures taken by the French Government. They were not arrived at in a reflective way and in full consideration of the conclusions of the expert group led by Sir Bruce Keogh. Only the latter could truly be said to close the knowledge base on PIP implant safety.

\section{CHECKLIST: How to use the argument from ignorance}

Features to observe...

- There must be good reasons to suppose that the closed world assumption holds in a particular case. Information that can help an arguer close a knowledge base should be provided. Dose markers and temporal markers are effective proxies for a closed knowledge base.

- There must be good reasons to suppose that the extensive search criterion holds in a particular case. Information that can help an arguer establish the extent of the search of a knowledge base should be provided. The expertise of a scientific review panel is one marker of a rigorous, comprehensive search process.

- An argument from ignorance can provide strong rational warrant for a conclusion or a claim. But it should not be made to carry an excessive evidential burden. This can be avoided by bringing forward other evidence that is independent of the argument from ignorance in support of a claim.

- An argument from ignorance is a defeasible form of argumentation that can be overturned as new evidence emerges. To this end, information should be conveyed and language should be adopted that conveys openness to the possibility of revision.

Features to avoid...

- Forced closure of the knowledge base is a common reason why the argument from ignorance fails. Quite often, closure can occur before an investigation or inquiry has even taken place, in which case it will be inevitable that there will be no evidence relating to a claim.

- Even when there is evidence in the knowledge base, this evidence may not relate to a proposition or a claim that is central to a 'no evidence' statement. However, the presence of this unrelated evidence may be used to force the closure of the knowledge base and present the base as complete.

- Fallacious arguments from ignorance are most often used to provide reassurances about the safety of food or a medical product when there is a 
breaking medical or health story that is likely to cause widespread public alarm. The overuse of 'no evidence' statements to frame reassurances about safety is often an indication that the argument is being used fallaciously.

- The absence of linguistic markers that suggest defeasibility is often a sign that the argument from ignorance is being used fallaciously. Markers such as at the present time and from the available evidence suggest that any claim based on a 'no evidence' statement is subject to revision should new evidence emerge. When these markers are noticeably absent, it should raise suspicion of a fallacious argument from ignorance.

\subsection{Ignorance as a Cognitive Heuristic}

It has been argued throughout the chapter that there is nothing inherently fallacious about the argument from ignorance. Rather, the argument is more or less rationally warranted under certain conditions. When there is a closed knowledge base and an extensively searched knowledge base, the absence of evidence that $p$ is true is reasonable grounds for concluding that $p$ is false. In this final section, we examine non-fallacious uses of the argument from ignorance in more detail. A proposition that cannot be located in a knowledge base following investigation of a question or issue and an extensive search of the base can quite legitimately be claimed to be false. But what makes us want to terminate an investigation and draw a conclusion based on ignorance rather than leave an inquiry open on an indefinite basis? After all, some evidence may be forthcoming that might definitively address an issue one way or another and avoid the need to draw an inference based on an absence of knowledge or evidence. The reason we do not allow investigations and other forms of inquiry to be continued on an indefinite basis is that reasoning is not a purely theoretical exercise. Rather, it is conducted within the practical sphere of action. In this sphere, we are all practically-situated cognitive agents who must make decisions and take courses of action in order to thrive and survive. None of us can afford the luxury of interminable cognitive deliberation, especially not if we want to find food and shelter and protect ourselves from various threats in our environment. Each of these goals requires actions to be performed within certain time constraints. And for this to occur, deliberation must come to an end.

Nowhere is the demand for action more keenly felt than in medicine and health. An infectious disease outbreak will not await the conclusion of exhaustive investigations by scientists and public health officials before it takes its grim toll on the lives of human beings. Preventative measures must often be taken in advance of the completion of an investigation and on the basis of scarce evidence. Decision-making in the absence of complete evidence is not an unusual state of affairs in medicine and health. Just such a scenario characterized the early public health response to HIV/AIDS before scientists had even succeeded in identifying a blood-borne virus as the causal agent of this novel disease. It was also the basis of the human Specified Bovine Offal (SBO) ban that was instituted in November 1989 and that was to prove a decisive measure in protecting human health from BSE. But even decision-making in the absence of evi- 
dence must be guided by some type of rational procedure. The argument from ignorance, I contend, is just such a procedure. Its function is that of a mental shortcut or cognitive heuristic that allows us to bridge gaps in our knowledge and arrive at a warranted claim that can become a basis for action. As events unfold and new evidence emerges, the claim in question may need to be rejected. The inherent defeasibility of the argument from ignorance means that its conclusion may be subject to revision. But until this is necessary, its conclusion can provide a tentative basis for action in a context where inaction could have serious consequences for human health. Inaction in the presence of extended deliberation can certainly avert an erroneous decision and course of action. But it is a poor pro-survival cognitive policy by any reasonable standard.

So the use of ignorance as a heuristic is motivated by the action orientation of the practical sphere, and particularly the need to terminate deliberation and pursue a course of action. Inquiry and other forms of deliberation place considerable demands on the resources, including attention and memory, of cognitive agents. These resources are finite in nature and must be sparingly deployed. Deliberation is also a time-intensive process as agents interrogate all aspects of a problem or issue. Through its termination of deliberation, the ignorance heuristic is achieving important economies in terms of time and resources for cognitive agents. This is the hallmark of all heuristics. They are 'fast and frugal' procedures that do not expend the resources of their more systematic counterparts in reasoning (Gigerenzer and Goldstein 1996). The scientist or health worker who must respond to an emerging infectious disease or other health problem can employ heuristics as a rational strategy for managing decision-making under the pressure of the practical sphere. The termination of deliberation and subsequent acceptance of a claim that the ignorance heuristic makes possible gives investigators some epistemic foothold in an incomplete evidential base. That foothold permits decisions and actions to be taken in the absence of evidence, such as when the human SBO ban was instituted in advance of any knowledge of the transmissibility of BSE to humans. The epistemic and practical gains that accrue from action in the absence of evidence outweigh the costs associated with error, and the costs associated with total inaction until such times as evidence becomes available. Against these alternatives, the ignorance heuristic is an effective use of our rational resources, and is not the 'fallacy' that many commentators have argued is the case.

\section{Chapter Summary}

Key points

- An argument from ignorance contains a premise that expresses a lack of knowledge or evidence that $p$ is true (alternatively, not- $p$ is true). From this premise, it is concluded that $p$ is false (alternatively, not- $p$ is false).

- The standard view of the argument from ignorance is that it is a fallacy, a type of weak, invalid, or bad reasoning. This has been its characterization by most philosophers throughout the long history of logic. 
- Informal logicians take a different view of the argument from ignorance. They claim that the argument is more or less rationally warranted in certain contexts of use or under certain conditions.

- Two conditions on the use of a rationally warranted argument from ignorance are the closed world assumption and the extensive search criterion. The closed world assumption requires that all information relevant to domain $D$ is contained in a knowledge base $K$. The extensive search criterion requires investigators to have conducted an exhaustive search of $K$.

- During argument evaluation, a number of linguistic markers can serve as proxies for the closed world assumption and extensive search criterion. They can help an arguer decide if the closed world assumption and extensive search criterion are fulfilled in a particular case.

- Other linguistic markers include expressions like currently, at this stage and to date. These temporal markers remind us that the argument from ignorance is a form of defeasible reasoning. We may need to reject the conclusion of an argument from ignorance as new evidence emerges.

- The argument from ignorance can function as a cognitive heuristic. It allows investigators to gain an epistemic foothold in an incomplete evidential base and accept a claim (albeit tentatively) that may be used as a basis for action. This is especially important in medicine and health where preventative measures to protect human health may need to be taken in the absence of evidence, or before the conclusion of an investigation or inquiry.

\section{Suggestions for Further Reading}

(1) Walton, D. (1995). Arguments from ignorance. University Park: Pennsylvania State University Press.

This is the only book-length treatment of the argument from ignorance. Walton examines everyday conversations in which the argument is used as a respectable form of reasoning and also situations in which it is fallacious. There is discussion of prominent cases such as the Salem witchcraft trials and McCarthy hearings. One of Walton's case studies examines the issue of the safety of silicone breast implants.

(2) Krabbe, E. C. W. (1995). Appeal to ignorance. In H. V. Hansen \& R. C. Pinto (Eds.), Fallacies: Classical and contemporary readings (pp. 251-264). University Park: Pennsylvania State University Press.

Krabbe examines two variants of the argument from ignorance. The first is a dialectical move that amounts to an unacceptable attempt to shift the burden of proof. The second is a principle for evaluating the outcome of a dialogue-forcing the proponent who fails to prove $p$ to accept not- $p$. Krabbe finds both these variants problematic. But he does not thereby conclude that all appeals to ignorance in dialogue are inherently fallacious. The chapter examines reasonable appeals to ignorance in the context of persuasion dialogue. 
(3) Cummings, L. (2015). Reasoning and public health: New ways of coping with uncertainty. Cham, Switzerland: Springer.

- Chapter 3 in this volume examines the argument from ignorance. The results of an experimental study involving 879 members of the public in the UK are reported. These subjects were asked to assess arguments from ignorance in which the closure of the knowledge base and the search of the knowledge base were varied. The argument is characterized as a cognitive heuristic that facilitates reasoning in contexts of uncertainty.

\section{Questions}

(1) An argument from ignorance contains a distinctive premise that uses a particular form of words. It states that there is no knowledge or evidence that $X$ is the case (alternatively, there is no knowledge or evidence that not- $X$ is the case). The following passages are taken from a number of different health sources. Identify the ignorance statement in each passage. Attempt to reconstruct this statement as the premise in an argument from ignorance:

(A)

Title Continuation of whooping cough vaccination programme in pregnancy advised

Source Press release, Department of Health and Social Care, United Kingdom, 16 July 2014

These findings are supplemented by the first large study of the whooping cough vaccine safety in pregnancy, published by the Medicines and Healthcare Products Regulatory Agency in the British Medical Journal. Reviewing data from around 18,000 vaccinated women from the Clinical Practice Research Datalink, the research found no evidence of risk from the vaccine to pregnancy or the developing baby, and rates of normal, healthy births were similar to those seen in unvaccinated women.

(B)

Title Response level for Middle East Respiratory Syndrome (MERS) lowered to "Alert"

Source Press release, Department of Health, Hong Kong, 1 August 2015

"According to the World Health Organization, the epidemiological pattern of the outbreak in Korea was similar to hospital-associated outbreaks that have occurred in the Middle East and there is no evidence of sustained community transmission of MERS-Coronavirus (MERS-CoV) in Korea", a spokesman for the Department of Health said.

(C)

Title No evidence of Gouléako and Herbert virus infections in pigs, Côte d'Ivoire \& Ghana

Source Academic article, Emerging Infectious Diseases, volume 21, issue 12, 2190-2193

A recent report suggested that two novel bunyaviruses discovered in insects in Côte d'Ivoire caused lethal disease in swine in South Korea. We conducted cell culture studies and tested serum from pigs exposed to mosquitoes in Côte d'Ivoire and Ghana and found no evidence for infection in pigs. 
(2) Temporal markers such as so far, currently and at the present stage can be used to indicate that a closed knowledge base may have to be revised if contrary evidence emerges at a later date. They are accordingly important markers of the defeasibility of claims that are based on an absence of evidence or knowledge. However, not all uses of these expressions suggest the defeasibility of claims that are based on an absence of evidence. The following statements are taken from the press releases of public health agencies in the UK and Hong Kong. They each contain the expression so far. For each instance of this expression, state if it is used to indicate the defeasibility of a claim that is based on an absence of evidence:

(A)

Title

E-cigarettes around 95\% less harmful than tobacco estimates landmark review

Source Press release, Public Health England, UK, 19 August 2015

An expert independent evidence review published today by Public Health England concludes that e-cigarettes are significantly less harmful to health than tobacco and have the potential to help smokers quit smoking. Key findings of the review include: There is no evidence so far that e-cigarettes are acting as a route into smoking for children or non-smokers.

(B)
Title
Hong Kong's readiness to fight avian influenza under review
Source
Press release, Department of Health, Hong Kong, 26 October 2005

The Permanent Secretary for Health, Welfare and Food, Mrs Carrie Yau, convened an interdepartmental meeting this afternoon to review Hong Kong's readiness to fight avian influenza amid fears that migratory birds might spread the virus with the approach of winter.

"The recent avian flu outbreak among birds and poultry is a cause for concern. However, there is no evidence to date confirming that the $\mathrm{H} 5 \mathrm{~N} 1$ virus is capable of efficient human-to-human transmission. So far, the series of preventive measures we adopted on local poultry farms, wholesale and retail markets are largely effective in countering the threat of avian flu", she said.

(C)

Title

Mosquito treatment in Ashford, Kent

Source

Press release, Public Health England, UK, 3 August 2017

Enhanced surveillance is being conducted at the site and in the vicinity, including the deployment of additional traps and larval sampling. So far, no further evidence of A. albopictus has been found, and there is no evidence so far that it has become established.

(3) The reconstruction and evaluation of any argument from ignorance requires knowledge of the conditions under which such an argument is more or less rationally warranted. Use your knowledge of these conditions to answer questions about the following extract from the Public Health Agency of Canada: 
Title Outbreak of E. coli infections linked to romaine lettuce

Source Press health notice, Public Health Agency of Canada, 9 February 2018

The Public Health Agency of Canada collaborated with provincial public health partners, the Canadian Food Inspection Agency and Health Canada to investigate an outbreak of Escherichia

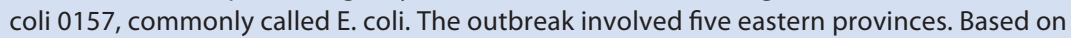
the investigation findings during the outbreak, exposure to romaine lettuce was identified as the source of the outbreak, but the cause of contamination was not identified. No individuals have had illness onset dates beyond December 12, 2017. As a result, the outbreak appears to be over, and the investigation has been closed [...] In total, there were 42 cases of E. coli 0157 illness reported in five eastern provinces: Ontario (8), Quebec (15), New Brunswick (5), Nova Scotia (1), and Newfoundland and Labrador (13). Individuals became sick in November and early December 2017. Seventeen individuals were hospitalized. One individual died. Individuals who became ill were between the ages of 3 and 85 years of age. The majority of cases (74\%) were female. There was no evidence to suggest that provinces in western Canada were affected by this outbreak.

(a) This extract contains a claim that is a potential premise in an argument from ignorance. What is that claim?

(b) Use the claim that you identified in response to (a) to construct an argument from ignorance.

(c) Does the argument from ignorance that you constructed in response to (b) have strong rational warrant? Provide a justification of your response.

(d) Can you identify any other claim apart from that in your response to (a) that expresses a lack of knowledge or ignorance?

(e) What information in the passage suggests that the knowledge base about the E. coli outbreak is unlikely to undergo revision at a later point in time?

\section{Answers}

\section{$\checkmark$ Exercise 2.1}

\section{(A)}

Temporal marker: Perfluoroalkyated substances have been used since the 1950s.

Dose marker: People have had considerable exposure to these substances in a range of common household products as well as industrial processes and firefighting foams.

(B)

Expertise marker: The epidemiological investigation was conducted by the Centers for Disease Control and Prevention in the United States, a body of experts in infectious disease control.

Scope marker: The study took in a large geographical region (15 states and territories) as well as a large number of births (nearly 1 million). 
(C)

Temporal markers: Mosquito surveillance has been conducted since 2010 at UK sea and airports and at motorway service stations since 2014.

2 Expertise marker: Surveillance has been conducted by an expert body, namely, Public Health England.

Scope marker: Surveillance has been conducted at more than 30 UK sea and airports and at motorway service stations in south east England.

\section{( $)$ Exercise 2.2}

\section{(A)}

Expertise marker: The investigation was conducted by state health authorities in Victoria, Australia.

Comprehensiveness marker: The investigation involved a detailed analysis of all food consumption histories.

(B)

Expertise marker: Two expert bodies were involved in an assessment of a potential relationship between human swine influenza vaccination and Guillain-Barré syndrome. They are the Centre for Health Protection and the Expert Group.

Comprehensiveness marker: The Expert Group reviewed all earlier cases of Guillain-Barré syndrome with a history of human swine influenza vaccination.

(C)

Expertise marker: Review of cases of listeriosis was conducted by an expert body, the National Institute for Communicable Diseases.

Comprehensiveness marker: All cases of listerioris in both private and public hospitals were examined as part of the review.

\section{$\checkmark$ Exercise 2.3}

(a) at this stage; so far; (b) currently; (c) at the moment; presently; (d) so far; (e) to date

\section{$\checkmark$ End-of-chapter questions}

Part (A):

There is no evidence that the whooping cough vaccine poses a risk to a developing baby.

Therefore, the whooping cough vaccine does not pose a risk to a developing baby.

Part (B):

There is no evidence of sustained community transmission of MERS-Coronavirus in Korea.

Therefore, sustained community transmission of MERS-Coronavirus in Korea does not occur. 
Part (C):

There is no evidence that pigs exposed to mosquitoes are infected with bunyaviruses. Therefore, mosquitoes do not transmit bunyaviruses to pigs.

(2)

Part (A): In this extract, so far is used to indicate the defeasibility of the following claim based on an absence of evidence: E-cigarettes do not act as a route into smoking for children and non-smokers.

Part (B): In this extract, so far is not used to indicate the defeasibility of a claim based on an absence of evidence. That role is performed by the expression to date, which indicates that the following claim may have to be revised at a later point in time: The H5N1 virus is not capable of efficient human-to-human transmission.

Part (C): In this extract, there are two instances of the expression so far. The first instance is used to indicate the defeasibility of the following claim: A. Albopictus does not exist. The second instance is used to indicate the defeasibility of the following claim: A. albopictus has not become established.

(3)

(a) There is no evidence that provinces in western Canada were affected by the outbreak.

(b) There is no evidence that provinces in western Canada were affected by the outbreak. Therefore, provinces in western Canada were not affected by the outbreak.

(c) The argument from ignorance does have strong rational warrant. This is because it is based on a closed knowledge base (the investigation into the outbreak is closed) that has been extensively searched (presumably) by the investigators of the outbreak.

(d) At the conclusion of the investigation, the cause of the contamination is not known.

(e) The extract says that no individuals experienced illness onset after 12 December 2017. This suggests that the outbreak is over and there is unlikely to be any need to revise the knowledge base at a later point in time.

\section{References}

Alderson, P., \& Roberts, I. (2000). Should journals publish systematic reviews that find no evidence to guide practice? Examples from injury research. British Medical Journal, 320, 376.

Brown, P., Cathala, F., Raubertas, R. F., Gajdusek, D. C., \& Castaigne, P. (1987). The epidemiology of Creutzfeldt-Jakob disease: Conclusion of a 15-year investigation in France and review of the world literature. Neurology, 37(6), 895-904.

Cummings, L. (2014). Informal fallacies as cognitive heuristics in public health reasoning. Informal Logic, 34(1), 1-37.

Cummings, L. (2015). Reasoning and public health: New ways of coping with uncertainty. Cham, Switzerland: Springer.

Gigerenzer, G., \& Goldstein, D. G. (1996). Reasoning the fast and frugal way: Models of bounded rationality. Psychological Review, 103(4), 650-669. 
Inungu, J., Mumford, V., Younis, M., \& Langford, S. (2009). HIV knowledge, attitudes and practices among college students in the United States. Journal of Health and Human Services Administration, 32(3), 259-277.

Jalloh, M. F., Sengeh, P., Monasch, R., Jalloh, M. B., DeLuca, N., Dyson, M., et al. (2017). National survey of Ebola-related knowledge, attitudes and practices before the outbreak peak in Sierra Leone: August 2014. BMJ Global Health, 2, e000285. — https://doi.org/10.1136/bmjgh-2017-000285.

Kelley, D. (2014). The art of reasoning: An introduction to logic and critical thinking (4th ed.). New York: W. W. Norton.

Keogh, B. (2012). Poly Implant Prothèse (PIP) breast implants: Final report of the expert group. London: Department of Health.

LeBlanc, J. (1998). Thinking clearly: A guide to critical reasoning. New York: W. W. Norton.

Lee, A. S.-Y., \& Gibbon, F. E. (2015). Non-speech oral motor treatment for children with developmental speech sound disorders. Cochrane Database of Systematic Reviews, Issue 3, Art. No.: CD009383.

Pennington, L., Parker, N. K., Kelly, H., \& Miller, N. (2016). Speech therapy for children with dysarthria acquired before three years of age. Cochrane Database of Systematic Reviews, Issue 7, Art. No.: CD006937.

Rescher, N. (1980). Scepticism: A critical reappraisal. Oxford: Basil Blackwell.

Robinson, R. (1971). Arguing from ignorance. The Philosophical Quarterly, 21(83), 97-108.

Toulmin, S., Rieke, R., \& Janik, A. (1984). An introduction to reasoning. New York: Macmillan.

Tsoumanis, A., Hens, N., \& Kenyon, C. R. (2018). Is screening for chlamydia and gonorrhoea in men who have sex with men associated with reduction of the prevalence of these infections? A systematic review of observational studies. Sexually Transmitted Diseases, 45(9), 615-622.

Vogel, A. P., Keage, M. J., Johansson, K., \& Schalling, E. (2015). Treatment for dysphagia (swallowing difficulties) in hereditary ataxia. Cochrane Database of Systematic Reviews, Issue 11, Art. No.: CD010169.

Walton, D. N. (1996). Argumentation schemes for presumptive reasoning. Mahwah, NJ: Erlbaum. 